\title{
PNLD Ciências: Um estudo para auxiliar o cumprimento dos critérios exigidos para a inclusão de objetos digitais de aprendizagem em coleções didáticas do ensino fundamental
}

A study of the compliance of requirements for digital learning objects in elementary school teaching materials

Marcos André Franco Martins, Doutor em Comunicação, Universidade Federal do Rio de Janeiro, marc.a.martins@gmail.com;

Alice Garcia-Gomes, Mestranda em Design, Universidade do Estado do Rio de Janeiro, alicegarciagomes@gmail.com.

\section{Resumo}

Este estudo tem como objetivo auxiliar o cumprimento dos critérios do PNLD que avaliam objetos digitais de aprendizagem. Interpretando três dos critérios à luz de teorias sobre aprendizagem, investigação científica e design da interação, são apresentadas recomendações e exemplos de objetos reais que cumprem ou não os critérios analisados.

Palavras Chave: Objeto de aprendizagem, avaliação, design de interação.

\section{Abstract}

This paper studies ways of attending to the criteria that assess digital learning objects in the Brazilian Textbook Program (PNLD). Interpreting three of the criteria in the light of theories about learning, scientific inquiry and interaction design, we present recommendations and examples of real objects that do or do not meet the criteria analyzed.

Keywords: Learning object, evaluation, interaction design. 


\title{
Introdução
}

O Programa Nacional do Livro didático (PNLD) passou em 2013 a divulgar critérios de avaliação específicos para objetos digitais de aprendizagem - como audiovisuais, jogos eletrônicos educativos, simuladores e infográficos animados. Contudo, o Ministério da Educação relatou que grande número dos objetos inscritos no programa foi reprovado, pois estes objetos não cumpriram os critérios do 'Guia de Livros Didáticos: PNLD 2014 Ciências'. Segundo este documento:

\begin{abstract}
"Infelizmente, na área de Ciências, a iniciativa não logrou sucesso porque a maioria desses objetos infringiu os critérios exigidos pelo Edital, tanto no aspecto pedagógico como técnico. Dessa forma, poucas coleções estão disponíveis com certos objetos educacionais digitais, notadamente audiovisuais e infográficos animados." (BRASIL, 2013).
\end{abstract}

As coleções didáticas podiam inscrever-se no programa em duas categorias: a 'tipo 2', que incluía objetos digitais de aprendizagem e a 'tipo 1 ', que não os incluía. Das 20 coleções aprovadas, apenas 5 são da categoria que inclui objetos digitais.

O presente artigo interpreta alguns dos critérios de avaliação divulgados pelo Ministério da Educação (MEC), na intenção de apresentar recomendações que auxiliem o seu cumprimento. Para tanto, são analisados exemplos de objetos reais que cumprem ou não os critérios selecionados. Páginas do documento elaborado pelo MEC, com a lista completa de critérios, encontram-se no anexo.

\section{A investigação científica}

Para o componente curricular Ciências, um dos critérios publicados pelo MEC verifica se os objetos de aprendizagem apresentam:

"1. Propostas de atividades que estimulem a investigação científica, por meio da observação, experimentação, interpretação, análise, discussões dos resultados, síntese, registros, comunicação e de outros procedimentos característicos da Ciência" (BRASIL, 2013).

Tendo em vista que, através deste breve texto, o MEC expõe o tema da investigação científica de maneira resumida, o presente artigo fornece informações adicionais retiradas da bibliografia especializada. Iniciaremos esclarecendo que a investigação científica é a atividade realizada pelos cientistas com o objetivo de produzir conhecimento científico. Segundo o filósofo e pedagogo John Dewey, o ensino deveria objetivar, entre outros aspectos, que se adquira a habilidade de compreender como os conteúdos estudados na escola foram construídos (apud CARMO, p.1, 2012). 


\section{V SILID IV SIMAR

A investigação científica é composta por diversas etapas, que serão explicadas adiante. $\mathrm{O}$ artigo também se aventura a analisar um objeto real que demonstra haver alcançado a tarefa de estimular a investigação científica. Para tanto, selecionamos o simulador digital da empresa ExploreLearning intitulado "Effect of Environment on New Life Form" (figura 1)ii.

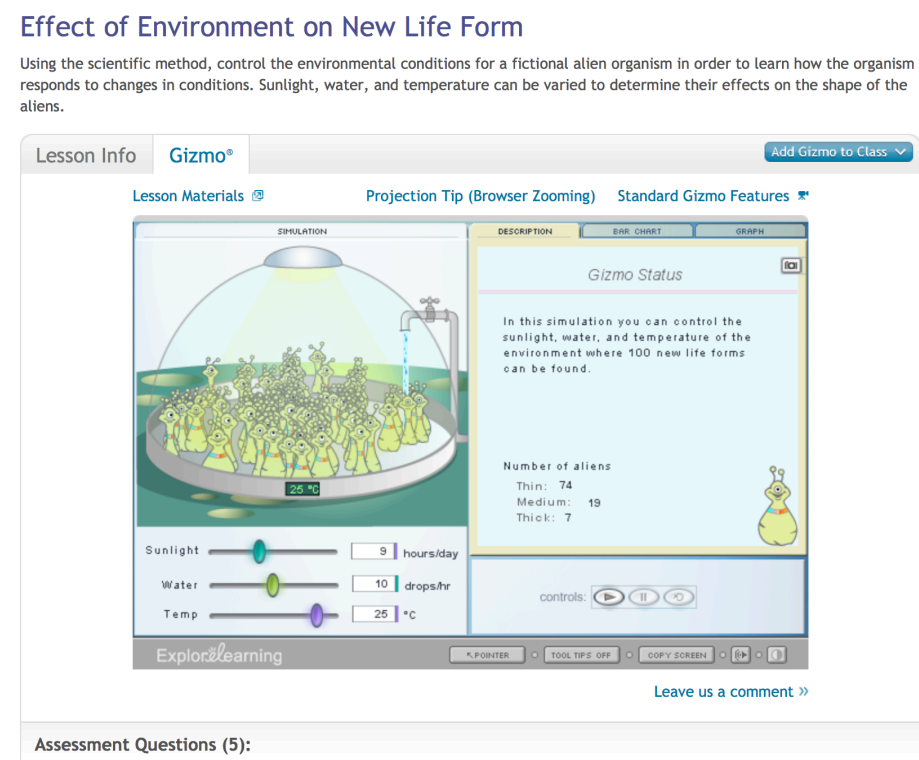

Figura 1: Objeto de aprendizagem da empresa ExploreLearning (sem data).

\section{As etapas da investigação científica e sua identificação em um objeto real}

Antes de apresentar as etapas da investigação científica, vale fornecer uma breve descrição sobre o objeto digital selecionado para análise. O acesso ao objeto dispensa a instalação de um programa ou aplicativo, sendo feito diretamente pelo navegador de internet, após a instalação de plugins (Adobe Shockwave e Flash Player). Dedicado a ensinar o tema dos experimentos controlados, assunto muito afim à própria investigação científica, este simulador apresenta dados numéricos sobre a quantidade de indivíduos de uma espécie de organismos fictícios. Na base da interface pode-se manipular três variáveis (luz solar, água e temperatura), o que permite controlar um experimento que tem por objetivo descobrir quais condições ambientais influenciam o formato corporal dos organismos.

De acordo com a revisão bibliográfica (CARMO, 2012; MORI, 2009; PINHO ALVES, 2000), as etapas da investigação científica podem ser subdivididas na seguinte lista (cuja ordem não é rígida):

-1. Observação ou identificação de um problema ou questão

-2. Consulta ao referencial teórico 


\section{V SILID IV SIMAR

- 3. Formulação de hipóteses

-4. Experimentação

\section{- 5. Registro e comunicação das conclusões}

Em um objeto digital interativo como o da figura 1, dificilmente há espaço para a etapa de observação no início da atividade planejada. O objeto usualmente fornece um problema ou questão já pre-formulado, que é apresentado em linguagem verbal (áudio e/ou texto) para ser o ponto de partida do objeto - como foi identificado pela letra a na figura 2 . É essencial que tal problema ou questão seja instigante, já que definirá grande parte da motivação ou desânimo dos estudantes em realizarem a investigação.

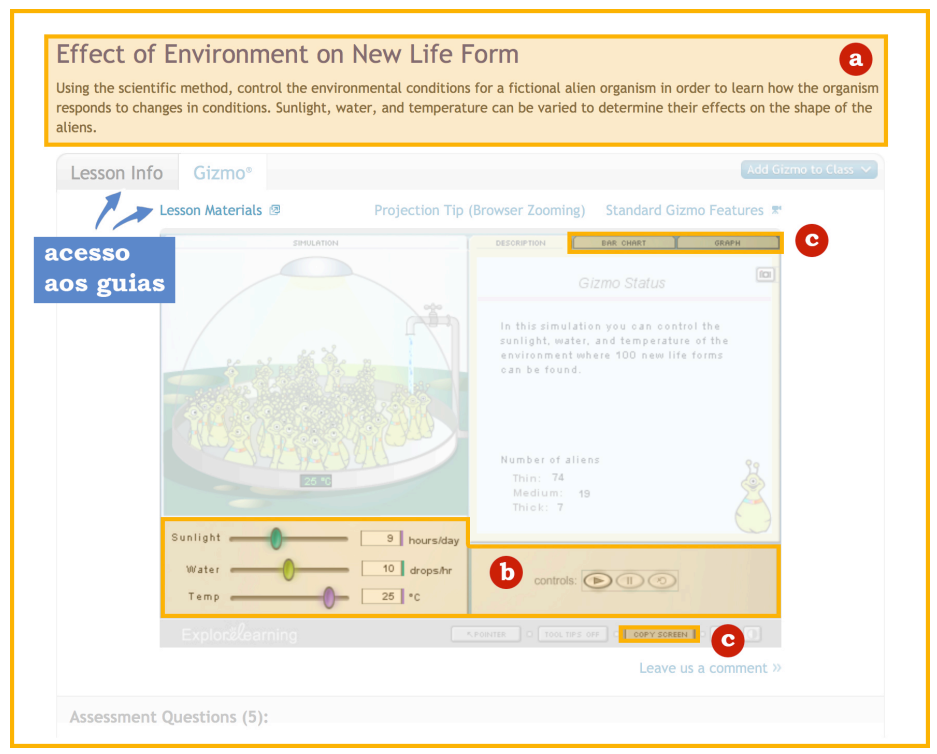

Figura 2: Etapas da investigação científica identificadas no objeto de aprendizagem da empresa ExploreLearning (mostrado na figura 1). A função das letras é evidenciar as etapas encontradas.

A segunda etapa - consulta ao referencial teórico - é o momento no qual os estudantes terão acesso às teorias formalizadas pelos cientistas, cuja compreensão é o próprio objetivo final de muitas atividades didáticas realizadas na escola. É importante que sempre haja menção verbal - no título, texto ou áudio - às teorias necessárias para a compreensão do conteúdo ensinado. No exemplo acima, esta etapa é abordada apenas no 'Guia de Orientação' do professor e do estudante.

Estes guias consistem em folhas de texto que orientam a utilização do objeto interativo (são elementos estáticos, sem interface interativa) e são acessados em outra página web, através do link e aba identificados na figura 2 pelas setas azuis. Nota-se assim que o foco deste objeto não está na exposição de informações teóricas (veremos à frente que seu foco está na atividade de experimentação). 
A etapa de formulação de hipóteses é o momento de estimular o pensamento a ir além do que é passível de ser observado em fenômenos específicos, buscando-se a generalização. Durante a geração de hipóteses, os estudantes devem ter espaço para pensarem por conta própria e discutirem entre si, sem que necessariamente cheguem a um consenso. A divergência de hipóteses é mesmo proveitosa para estimular a realização do trabalho experimental.

No objeto analisado, a formulação de hipóteses é abordada na folha de orientação do estudante, na forma de perguntas discursivas a serem preenchidas. Nesta etapa, é interessante a escolha pela forma discursiva, pois ela possibilita que os estudantes pensem de maneira autônoma em vez de visualizarem possíveis hipóteses a serem selecionadas, como seria o caso em questões de múltipla escolha.

A etapa de experimentação é frequentemente um dos momentos mais cativantes da investigação científica, já que aproxima os estudantes da postura de "construir" conhecimento. Antes dos grandes projetos de ensino, que iniciaram a renovação do ensino de ciências na década de 60, as escolas brasileiras encaravam a experimentação enquanto a atividade de demonstrar experimentos nos laboratórios. Nestas demonstrações, o papel dos estudantes era o de observadores passivos (PINHO ALVES, 2000, p. 43 e 210).

Atualmente, almeja-se que a experimentação praticada em sala de aula envolva a participação ativa dos estudantes, a articulação dos saberes novos com os antigos, o incentivo a discussões entre alunos, a socialização do trabalho experimental entre todos os integrantes da turma e o estímulo ao pensamento crítico. No exemplo estudado, a experimentação pode ser apontada na letra $b$ da figura 2, onde se encontram controladores analógicos e numéricos que permitem manipular variáveis.

Vale apontar que, em outros objetos de aprendizagem, a manipulação de variáveis também poderia ser projetada de outras maneiras. Em vez de interagirem com controladores, os usuários poderiam manipular elementos pictóricos, por exemplo, ou até mesmo as linhas de um gráfico.

A última etapa da investigação científica - o registro e comunicação das conclusões - é o momento dos estudantes tomarem nota de suas observações, dados coletados e conclusões. É importante que o registro permeie todas as etapas da investigação científica, pois, caso contrário, as observações dos estudantes podem confundir-se com o que pretendiam inferir, levando a vieses nas observações (AAAS, 1989, apud CARMO, p. 10, 2012).

No exemplo estudado, espaços específicos para registrar os dados da simulação estão previstos na folha de exploração do estudante. Além disso, é possível afirmar que as funcionalidades de visualização de gráficos e de captura de tela (letra $c$ da figura 2) também contribuem para o registro e comunicação das conclusões. 
Como foi explicado ao longo do texto, é importante que a atividade didática proposta pelo objeto digital aborde todas as etapas da investigação científica. Os guias de orientação didática são um recurso importante para se incluir etapas não abordadas na interface interativa do objeto. Se todas as etapas forem abordadas na interface interativa do objeto - através do sequenciamento das informações ou da utilização de botões (ou abas) - o objetivo central do objeto pode tornar-se confuso.

Por exemplo: se o objetivo central de um simulador é permitir a experimentação (como é o caso do simulador da figura 1), é interessante que os controladores que proporcionam a experimentação recebam destaque e sejam vistos desde os primeiros momentos de interação. Isto seria dificilmente alcançado se todas as etapas da investigação científica estivessem presentes na interface, disputando a atenção dos usuários.

Portanto, algumas destas etapas, como a formulação de hipóteses e a apresentação de informações teóricas, por exemplo, podem ser alocadas nas páginas dos guias de orientação didática, evitando-se assim que o foco na experimentação fique disperso ou que a interface fique sobrecarregada de informações.

\section{Instruções e feedback}

Após havermos abordado o tema da investigação científica, trataremos agora de dois outros assuntos que também são mencionados na lista de critérios do PNLD: instruções e feedback. Os critérios que abordam estes assuntos são: "Todos os jogos e simuladores deverão apresentar instruções claras e de fácil leitura durante todas as atividades" ( ${ }^{024}$ ) e "Todas as atividades deverão apresentar feedback e dicas que ajudam o usuário no processo de aprendizagem" ( $n^{025}$ ).

Refletindo sobre a razão por trás do primeiro destes critérios, é fácil induzir que, sem a presença de instruções, ficaria a cargo do professor a tarefa de entender o funcionamento do objeto, além de planejar como ele integraria a nova atividade à sua aula original. Isto com certeza diminuiria as chances de utilização do objeto, já que acrescentaria tarefas a profissionais já frequentemente sobrecarregados.

Uma das recomendações deste artigo é que todo tipo de objeto digital de aprendizagem tenha tanto instruções técnicas quanto orientações didáticas muito claras e bem apresentadas. Em relação às instruções técnicas, é válido incentivar que elas não repliquem a linguagem utilizada no conteúdo didático do objeto. É mais adequado utilizar uma linguagem simples, com vocabulário diferente e acessível, para que a ação possa ser realizada mesmo pelo estudante que ainda não tiver compreendido a matéria. 


\title{
D V SILID IV SIMAR

O tema das instruções também é abordado pelo teórico em usabilidade Jakob Nielsen. 'Ajuda e Documentação' é uma das dez heurísticas para design de interface desenvolvidas pelo autor. Sobre este tópico, Nielsen declara:

\begin{abstract}
"Mesmo sendo melhor que o sistema possa ser utilizado sem documentação, pode ser necessário fornecer ajuda e documentação. Qualquer informação deste tipo deve ser de fácil procura, focada na tarefa do usuário, listar passos concretos a serem realizados e não ser muito longa"iii. (NIELSEN, 1995).
\end{abstract}

Além das características citadas pelo autor, lembramos a importância de que a interface permita retornar ao estágio anterior rapidamente, após serem acessadas as instruções. Recomendamos evitar instruções localizadas em páginas isoladas, que não tenham botão de voltar. Uma escolha projetual favorável para instruções de pequeno volume é a de fornecer uma pequena janela (pop-up) que abre somente quando solicitado pelo usuário e sobrepõe-se ao objeto, podendo também ser movimentada para visualização de áreas por ela ocultadas (SHERWIN, 2015).

\section{Identificação de instruções e feedback em um objetos reais}

O objeto de aprendizagem "Velocidade da Reação" (também denominado "Rapidez da Reação") foi aprovado no PNLD 2014 (BRASIL, 2013, p. 89) e debruça-se em ensinar como a temperatura, a superfície de contato e outros aspectos influenciam na velocidade de certas reações químicas. Classificado pelo PNLD enquanto 'hipermídia' e utilizado aqui enquanto exemplo para a discussão, o objeto fornece suas orientações junto ao próprio conteúdo didático, na forma de curtas frases entre parênteses (figura 3).

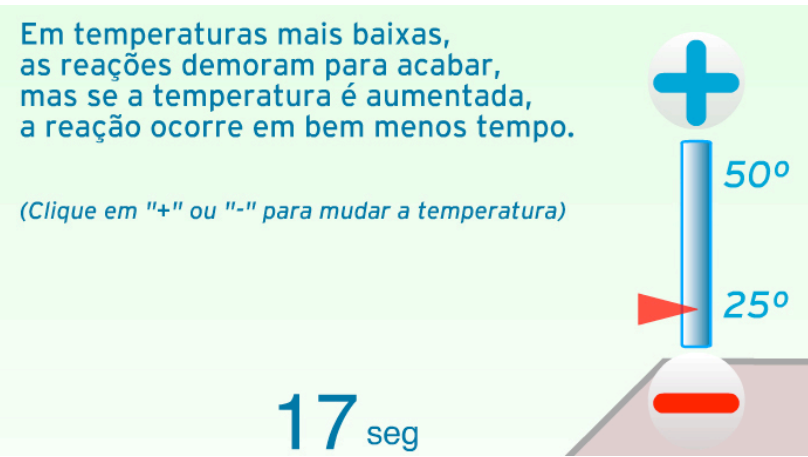

Figura 3: Detalhe do objeto digital "Velocidade da reação", mostrando uma das instruções entre parênteses (EDIÇÕES SM, 2012).

A partir da citação de Jakob Nielsen anteriormente apresentada, notamos ser vantajoso optar pelo uso de instruções curtas. Neste caso, contudo, observamos que a extrema economia de palavras deixa de lado informações essenciais à compreensão da interface. É possível ver na figura 3 uma instrução que orienta o 
usuário a clicar no botão de "+" ou de "-" (menos). A presença de tal instrução, no entanto, não esclarece que a ação só deve ser realizada após o término da animação, exibida automaticamente na parte direita da tela - no recipiente com água que pode ser visto na figura 4. Como resultado, ao terminar de ler a frase, o usuário tende a clicar no botão de "+" enquanto a animação ainda está em curso. Isto acidentalmente aciona a animação correspondente à temperatura mais alta, interrompendo a anterior antes do fim.

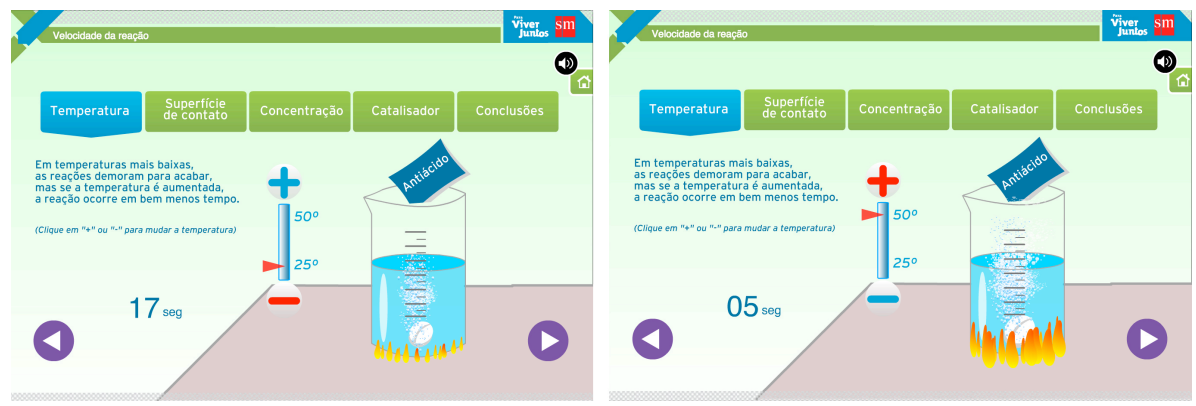

Figura 4: Duas telas do objeto digital (EDIÇÕES SM, 2012).

Este tipo de situação frustra o usuário e poderia ser evitada de duas maneiras. A primeira consistiria em acrescentar algumas palavras na instrução textual de forma a explicar que os botões só devem ser acionados após o fim da animação. A segunda alternativa, ainda mais eficaz, seria a de desativar o botão de troca de temperatura durante a exibição da animação (deixando os botões transparentes ou ocultando-os). O recurso de inativar botões em momentos específicos é utilizado em numerosas interfaces e evita erros de interação a partir de uma solução simples, que dispensa longas instruções verbais e contribui para uma interface autoexplicativa.

O segundo assunto abordado neste trecho do artigo - o feedback (presente no supracitado critério n025 do PNLD) - é um tema muito estudado na área do design da interação - campo dentro do qual costuma referir-se à "informação relativa ao uso de um elemento pelo usuário" (PIMENTEL \& FUCKS, p.286, 2012). Em páginas web, por exemplo, os links ou botões que já foram clicados frequentemente aparecem em outra cor, o que constitui uma forma de feedback da interação.

Neste contexto, contudo, o PNLD pode estar referindo-se a outro tipo de feedback: o feedback da aprendizagem. Uma das formas mais comuns deste tipo de feedback em objetos digitais de aprendizagem é a presença de perguntas para testar o conhecimento dos usuários e, com grande frequência, estas perguntas são em formato de múltipla escolha. Por outro lado, também foram encontrados objetos que utilizam o formato discursivo, como é o caso de diversas animações interativas e simuladores divulgados no domínio "scootle.edu.au". Nestes casos, os estudantes escrevem suas respostas em caixas de texto e, ao final da atividade, têm acesso a 
um relatório com suas respostas. Um exemplo de objeto deste domínio que utiliza tanto perguntas no formato objetivo quanto discursivo denomina-se "Fair Test" iv (sem data). O formato discursivo é interessante, pois, além de estimular o pensamento autônomo, também exercita a capacidade de redigir textos.

Além da questão do feedback, o mesmo critério no 25 faz menção a 'dicas para ajudar no processo de aprendizagem'. Um tipo de 'facilitador' do processo de aprendizagem são perguntas que precedem a atividade principal e que estimulam os estudantes a recordarem dos seus conhecimentos prévios. Segundo David Ausubel, aprendemos a partir do que já sabemos - o que foi denominado de aprendizagem significativa - e o conhecimento prévio, isoladamente, é o fator de maior influência no processo de aprendizagem (1963, apud MOREIRA, p. 2 e 4, 2010).

Portanto, é vantajoso que os objetos digitais incorporem perguntas ou menções relativas aos conhecimentos prévios dos estudantes. De preferência, estas perguntas devem ser incorporadas à parte principal da interface, de modo a facilitarem o contato com a matéria ensinada. Uma alternativa é dispô-las numa parte secundária, acessada através de link ou botão, como a folha 'Guia de Orientação' explicada no início do artigo.

\section{Conclusão}

O artigo interpretou três critérios de avaliação presentes no 'Guia de Livros Didáticos: PNLD 2014 Ciências', apresentando objetos digitais de aprendizagem reais que servem de exemplos para ilustrar as observações apontadas. Ao longo do texto, foram expostas recomendações que auxiliam no cumprimento destes critérios e que se fundamentam em referências bibliográficas sobre aprendizagem, investigação científica e design da interação.

Dentre as recomendações apontadas pelo artigo, a primeira indica que todas as etapas da investigação científica devem ser abordadas nos objetos digitais. Por isso, tais etapas foram detalhadas no texto e identificadas no exemplo real selecionado, a partir de uma imagem que aponta onde cada etapa está presente na interface. Foi indicado que uma das etapas de grande potencial para exploração em objetos digitais é a da experimentação, que pode ser realizada pela manipulação de variáveis - a partir de controladores analógicos e numéricos ou mesmo diretamente por elementos pictóricos ou gráficos que geram mudanças na simulação.

Outra recomendação apontada diz respeito ao design de interação: Destacouse o recurso de inativar botões em certos momentos da interação, de forma a evitar erros e frustrações. Também destacou-se que, apesar de ainda pouco usual, existe a possibilidade de fornecer feedback da aprendizagem a partir de perguntas no formato discursivo, integradas à interface interativa do objeto. Por fim, foi recomendada a inclusão de perguntas ou menções relativas aos conhecimentos 
prévios dos estudantes, o que está de acordo com a teoria da aprendizagem significativa.

Notas

' O conteúdo sobre investigação científica presente neste artigo foi publicado nos anais do $1^{\circ}$ Simpósio de Pós-graduação em Design da ESDI, no artigo "Objetos Digitais de Aprendizagem e o estímulo à investigação científica" (GARCIA-GOMES, 2015).

ii A reprodução das figuras analisadas neste artigo, apresentadas apenas para fins de estudo e crítica, não constitui ofensa aos direitos autorais, de acordo com a Lei no 9.610/98, Art. 46, inciso III.

iii Tradução do autor para o texto em inglês: "Even though it is better if the system can be used without documentation, it may be necessary to provide help and documentation. Any such information should be easy to search, focused on the user's task, list concrete steps to be carried out, and not be too large".

iv Este objeto digital pode ser visto no link: http://www.scootle.edu.au/ec/viewing /L8487/index.html.

\section{Referências Bibliográficas}

BRASIL. Ministério da Educação. Secretaria de Educação Básica. Guia de livros didáticos: PNLD 2014: Ciências: Ensino Fundamental: Anos Finais. Brasília. In: FNDE, 2013. Disponível em <http://www.fnde.gov.br/programas/livrodidatico/guias-do-pnld/item/4661-guia-pnld-2014> Acesso em 14 mai. 2015.

CARMO, K. V. do. Habilidades e procedimentos da investigação científica: percepções de um grupo de licenciandos em ciências biológicas a partir de uma sequência didática em biologia celular e molecular. Dissertação (Mestrado em Ensino de Ciências) - Universidade de Brasília, Brasília, 2012.

EXPLORELEARNING. Effect of environment on new life form. In: ExploreLearning.com, Sem data. Disponível em<http://www.explorelearning.com /index.cfm?method=cResource.dspDetail\&ResourceID=397> Acesso em: 24 abr. 2015.

MOREIRA, M. A. Aprendizagem significativa crítica. In: UFRGS, 2000. Disponível em <http://www.if.ufrgs.br/ moreira/apsigcritport.pdf>. Acesso em: 1 mai. 2015.

MORI, R. C. Análise de experimentos que envolvem química presentes nos livros didáticos de ciências de $1^{a}$ a $4^{a}$ séries do ensino fundamental avaliados no PNLD/2007. São Carlos: Dissertação (Mestrado) - Instituto de Química de São Carlos, Universidade de São Paulo, 2009. 
NIELSEN, J. 10 Heuristics For User Interface Design. In: NN/g Nielsen Norman Group, 1995. Disponível em <http://www.nngroup.com/articles/ten-usabilityheuristics/>. Acesso em: 15 mai. 2015.

PIMENTEL, M.; FUKS, H. Sistemas Colaborativos. Rio de Janeiro: ElsevierCampus-SBC, 2012.

PINHO ALVES, J. Atividades experimentais - do método à prática construtivista. Tese (Doutorado em Educação) - Centro de Ciências da Educação, Universidade Federal de Santa Catarina, Florianópolis, 2000.

SHERWIN, K. Pop-ups and Adaptive Help Get a Refresh. In: NN/g Nielsen Norman Group, 2015. Disponível em <http://www.nngroup.com/articles/pop-upadaptive-help/> Acesso em: 24 abr. 2015.

VELOCIDADE DA REAÇÃO. In: PETILLO NERY, A. L et al. Para viver juntos: Ciências, 90ano: Ensino Fundamental, $3^{a}$ Ed. São Paulo: Edições SM, 2012. Disponível em <http://tics.edicoessm.com.br/tics/playerTE/index.html?typ=anima\& col=iv\&disc $=$ cie\&prod $=12 \&$ cont $=48 \_q m \_9 \_v j \_o d a \_i n d \& t i t=V e l o c i d a d e \% 20 d a \% 20 r$ ea\%C3\%A7\%C3\%A3o>. Acesso em: 3 jun. 2015. 


\section{Anexo} como foi feita a avaliação das coleções de Ciências inscritas no Programa Nacional do Livro Didático - PNID/2014 e por que as coleções apresentadas no Guia foram consideradas de qualidade, ainda que algumas com certas restriçōes.

A avaliação fundamentou-se em todos os critérios definidos no Edital de Convocação do PNLD 2014, elaborado pelo Ministério da Educação.

A ficha de avaliação (que se encontra ao final do Guia), que permitiu unificar o "olhar" de cada avaliador em torno das diversas coleçōes, foi organizada em torno das características gerais (ou categorias) de análise apresentadas abaixo

Para cumprir a exigência de qualidade da educação, os livros didáticos inscritos no PNLD são submetidos a um processo de avaliação pedagógica, pautado por critérios eliminatórios, comuns a todas as disciplinas curriculares e específicos de cada uma delas. Tais requisitos não podem ser infringidos para que uma obra possa ser adquirida e distribuida pelo MEC. Os critérios eliminatórios comuns do PNLD 2014 são:

1. respeito à legislação, às diretrizes e às normas oficiais relativas ao ensino fundamental:

U. observância de princípios éticos necessários à construção da cidadania e ao convivio social republicano

III. coerência e adequação da abordagem teórico-metodológica assumida pela coleção, no que diz respeito à proposta didático-pedagógica explicitada e aos objetivos visados:

IV correção e atualização de conceitos informações e procedimentos;

V. observância das características e finalidades específicas do Manual do Professor e adequação da coleção à linha pedagógica nele apresentada;

VI. adequação da estrutura editorial e do projeto gráfico aos objetivos didáticopedagógicos da coleção.

Além desses critérios eliminatórios comuns a todas as áreas do PNLD para o componente curricular Ciências foi observado se a coleção apresenta:

1. propostas de atividades que estimulem a investigação cientifica, por meio da observação, experimentação, interpretação, análise, discussões dos resultados, síntese, registros, comunicação e de outros procedimentos característicos da Ciência:

2. temas de estudo, atividades, linguagem e terminologia científica adequados ao estágio de desenvolvimento cognitivo dos estudantes: 
3. iniciação às diferentes áreas do conhecimento científico, assegurando a abordagem de aspectos centrais em física, astronomia, química, geociências, ecologia, biologia e saúde:

4. articulação dos conteúdos de Ciências com outros campos disciplinares:

5. a produção do conhecimento científico como atividade que envolve diferentes a produção do conhecime
pessoas e instituições:

6. a história da ciência muito além de nomes ou datas, explorando o contexto onde ocorreu a produção científica:

7. textos e atividades que colaborem com o debate sobre as repercussões relações e aplicações do conhecimento cientifico na sociedade:

8 orientação para o desenvolvimento de atividades experimentais factíveis, com orientação para o desenvolvimento de atividades exp
resultados confiáveis e interpretação teórica correta;

9. incentivo a uma postura de respeito ao ambiente, conservação e manejo corretos:

10 orientações claras e precisas sobre os riscos na realização dos experimentos e atividades propostos visando garantir a integridade física de alunos, professores e demais pessoas envolvidas no processo educacional;

11. propostas de atividades que estimulem a interação e participação da comunidade escolar, das famílias e da população em geral;

12. propostas de visitas a espaços que favoreçam o desenvolvimento do processo de ensino e aprendizagem (museus, centros de ciências, parques zoobotânicos, universidades, centros de pesquisa e outros)

13. propostas de uso de tecnologias da informação e comunicação:

14. orientações para utilizar textos, vídeos, objetos de aprendizagens e outros recursos disponiveis na rede internet, em especial aqueles disponiveis nos Portais do MEC e da Capes

15. propostas pedagógicas lúdicas para o ensino de ciências.

\section{Manual do Professor}

$\mathrm{Na}$ avaliação das coleç̃̃es de Ciências, será observado se o Manual do Professor:

valoriza o papel do professor como um problematizador orientando-o para que apresente novas propostas atraentes de investigações científicas

2. propõe outras atividades e experimentos, além dos indicados no livro do aluno:

3. propõe a integração das linguagens, especialmente as midiáticas e o uso de computadores para pesquisa na Internet, simulações, argumentação e registro apresenta referências bibliográficas de qualidade e facilmente acessiveis estimulando o professor para leituras complementares;

5. apresenta propostas de avaliação condizentes com os pressupostos teóricometodológicos que nortearam a proposição das atividades e seleção dos conteúdos do livro do aluno. 


\section{V SILID IV SIMAR}

PUC-Rio - Dias 28, 29 e 30 de julho de 2015

Critérios para a avaliação dos conteúdos multimídia

De acordo com o Edital, foi avaliado cada um dos Objetos Educacionais Digitais presentes nos DVDs das obras, observando-se as seguintes características:

1. $\bigcirc$ foco principal dos objetos educacionais digitais a serem utilizados nos conteúdos multimídia deve ser o de facilitar o processo de aprendizagem dos alunos.

2 Cada DVD ROM deverá conter no ato da inscrição das coleções, entre 10 e 20 conteúdos multimídia por volume da coleção. Cada conteúdo multimídia poderá conter de l a 5 objetos educacionais digitais, escolhidos entre as categorias: audiovisuais, jogos eletrônicos educativos, simuladores ou infográficos animados.

3. Cada um desses objetos educacionais digitais que compöem um conteúdo multimídia não deve ser dependente um do outro. No caso de algum deles ser excluído, uma vez que serão avaliados individualmente, isso não poderá implicar o comprometimento da compreensão pedagógica do conteúdo multimídia. Em ocorrendo tal situação, todo o conteúdo multimídia relacionado a esses objetos educacionais digitais será excluído do DVD ROM

4. Um objeto educacional digital poderá remeter, internamente, a outros objetos educacionais digitais Por exemplo. um simulador poderá remeter a um video ou a um infográfico. Nesse caso, todos esses outros objetos, para efeito de remuneração, serão considerados apenas um, sendo remunerado aquele de maior complexidade

5. Os conteúdos deverão ser desenvolvidos em mídia DVD ROM, autorada com menu de navegação com iniciação automática. O menu deve ser autoexplicativo e permitir que o usuário (aluno ou professor) navegue pelos conteúdos sem necessitar auxílio. A autoração deverá ser refeita caso um ou mais conteúdos venham a ser eliminados.

6. Os submenus, tutoriais e guias devem fazer parte dos objetos educacionais digitais e devem ter navegação própria e independente dos demais objetos e conteúdos.

7. Cada conteúdo e cada objeto educacional digital deverá ser identificado com nome icone e numeração correspondente à utilizada no livro. Os icones de identificação deverão conter hipertextos explicativos (acionados pela posição do cursor sobre o objeto, mouse over), principalmente as identificações de página e assunto correspondentes.

8. O menu de navegação do DVD ROM deverá possuir recursos que proporcionem acessibilidade aos portadores de deficiência como, no minimo, contraste aumento do tamanho da fonte dos textos. HTML sob os padrões webstandard (caso seja feito nesse formato)

9. $\bigcirc$ DVD ROM deverá funcionar perfeitamente nos principais sistemas operacionais. Especificamente no caso das escolas públicas brasileiras, a referência deverá ser aquela feita pelo Prolnfo (especificações constantes do endereco eletrônico: $h t t p$ //portal.mec.gov.br/index.php?option=com content\&vi $e w=$ article $\& i d=244 \&$ Itemid $=460$ ) 
10. Os conteúdos do DVD ROM não poderão ser usados para a autopromoção de professores ou atores

11. Cada categoria de objeto contém critérios que são descritos visando 3 graus de complexidade: alta complexidade, média complexidade e baixa complexidade

12. Cada uma das categorias listadas abaixo deve se estruturar a partir de objetivos educacionais bem definidos e clareza nas competências a serem desenvolvidas pelos estudantes.

13. Os objetivos pedagógicos devem nortear a escolha da categoria de mídia para a produção do objeto educacional digital.

14 Os temas/assuntos tratados nos conteúdos multimidia e nos objetos educacionais digitais devem ser bastante atraentes $e$ adequados ao público-alvo, considerando, para isso, as atividades de maior dificuldade de aprendizagem por parte dos alunos ou dificuldade de ensino por parte dos professores. Atividades de fácil compreensão ou amplamente explicadas por meio de texto impresso, como os existentes no livro didático, não deverão ser o foco de produção para este DVD ROM.

15. Os objetos educacionais digitais contidos no DVD ROM deverão ser passiveis de uso em computadores pessoais de mesa e portáteis

16. Os objetos contidos no DVD ROM poderão ser usados em laboratórios on outros espaços, tanto nas escolas como nas residências de professores e alunos.

17. Os conteúdos não poderão conter arquivos executáveis (exe), e o acesso deve ser facultado em diferentes sistemas operacionais.

18. A coleção impressa, em formato digital, não será aceita como conteúdo deste DVD ROM.

19. Na produção de conteúdos multimídia e de objetos educacionais digitais deverá ser respeitada a lei de direitos autorais e a lei de propriedade intelectual de programas de computador

20. Os objetos do DVD ROM do professor deverão ser os mesmos do DVD ROM do aluno, acrescidos de uma guia de uso pelos professores (manual do professor). No caso de livros de línguas estrangeiras a versão do professor deve conter além do DVD ROM, um CD de áudio.

21. Os vídeos deverão ter, no máximo 10 (dez) minutos de duração

22. Formatos: (Ficcional ou Não-ficcional: Seriado, Minisérie, Documentário e Animação) Não será aceito o formato de vídeoaula, onde um único interlocutor (professor) narra uma matéria. Os conteúdos devem oferecer experiências que professores e alunos normalmente não encontram em uma sala de aula.

23. Além da captação a produção poderá se utilizar de recursos variados de animação, tais como: Stop motion. 3d 2d composição e motion graphics. A fim de facilitar o entendimento do conteúdo a produção deve, ainda, prever outros recursos audiovisuais, como imagens de arquivo, aplicação de videografismos, textos e gráficos que complementem as explicações.

24. Todos os jogos e simuladores deverão apresentar instruções claras e de fácil leitura durante todas as atividades

25. Todas as atividades deverão apresentar feedback e dicas que ajudam o usuário no processo de aprendizagem. 
26. Todos os jogos e simuladores deverão apresentar atividade(s) interessante(s) desafiadora(s) o suficiente para motivar o usuário a participar da atividade.

27. Assegurar a percepção do texto e dos elementos gráficos, quando vistos sem cores.

28. Utilizar corretamente a marcação dos conteúdos com os elementos estruturais adequados.

29. Apresentar os conteúdos por meio de estilos e atributos de destaque

30. Indicar claramente o idioma utilizado, por meio de marcações que facilitem a pronúncia e a interpretação de abreviaturas ou texto em língua estrangeira.

31. Apresentar conteúdos dotados de novas tecnologias, que sejam transformados harmoniosamente, assegurando a acessibilidade mesmo quando as tecnologias mais recentes não forem suportadas ou tenham sido desativadas.

32. Utilizar soluções de acessibilidade transitórias, para que as tecnologias de apoio ou mais antigas funcionem corretamente.

33. Fornecer informações de contexto e orientações para ajudar professores/ alunos a compreenderem elementos complexos.

34. Fornecer mecanismos coerentes e sistematizados com informações de orientação para aumentar as possibilidades de o professor/aluno encontrar facilmente o que procura.

35. Prover acessibilidade direta de interface do usuário integrada: assegurar princípios de design para acessibilidade, acesso independente de dispositivos, operacionalidade por teclados e emissão automática de voz.

Cada obra impressa foi analisada individualmente por dois avaliadores. Após essa análise, todas as duplas de avaliadores reuniram-se para a consolidação de suas análises junto com os coordenadores e o membro da Comissão Técnica do MEC. Esse foi um momento de intensa participação coletiva e troca de concepções e conhecimentos. Muito diálogo e debates importantes acerca das especificidades do ensino de Ciências e dos sucederam-se em busca das melhores soluções. Ta processo deve ainda estar acontecendo agora no momento de escolha ou irá acontecer no âmbito escolar durante o periodo de utilização da obra.

Com base no processo de análise adotado, passou-se à elaboração dos pareceres de aprovação e exclusão de todas as coleções avaliadas. A etapa fina consistiu na elaboração das resenhas das coleçōes aprovadas

Na última fase do processo, foram realizados vários encontros da Coordenação para uma análise minuciosa dos pareceres e resenhas e a elaboração do Ouadro Comparativo para auxiliar na escolha da coleção e organização geral deste Guia.

Os conteúdos multimídia foram avaliados por outra equipe formada pelos coordenadores e pessoal técnico especializado que procedeu ao preenchimento de uma ficha de avaliação contemplando as partes técnica e pedagógica dos DVDs.

É importante que no planejamento de suas aulas seja considerada a essência de seu próprio projeto pedagógico e as condições para colocá-lo em prática. Subsídios 